\title{
Synthesis of Phosphorus Included Multiwalled Carbon Nanotubes by Pyrolysis of Sucrose
}

\author{
Gokce Kucukayan-Dogu, ${ }^{\dagger}$ H. Sener Sen, ${ }^{\ddagger}$ Hilmi Yurdakul, ${ }^{\S}$ Servet Turan, ${ }^{\prime}$ Oguz Gulseren, ${ }^{\ddagger}$ \\ and Erman Bengu*, ${ }^{*}$ \\ ${ }^{\dagger}$ Materials Science and Nanotechnology Graduate Program, Bilkent University, Ankara, Turkey \\ ${ }^{\ddagger}$ Department of Physics, Bilkent University, Ankara, Turkey \\ ${ }^{\S}$ Department of Materials Science and Engineering, Dumlupinar University, Kutahya, Turkey \\ "Department of Metallurgical and Materials Engineering, Anadolu University, Eskisehir, Turkey \\ ${ }^{\perp}$ Department of Chemistry, Bilkent University, Ankara, Turkey
}

ABSTRACT: Multiwalled carbon nanotubes (MWCNT) were synthesized by a pyrolysis route which involves a dehydration step using phosphoric acid. The resultants were found to be mostly containing amorphous carbon with scattered MWCNTs using scanning electron and transmission electron microscopy techniques. These MWCNTs were smaller in size and limited in quantity compared to the ones synthesized using other common precursors. Energy dispersive X-ray and electron energy loss spectroscopy analysis indicated the presence of phosphorus both at the MWCNT sidewalls and in the catalyst particles encapsulated inside the MWCNTs. In addition, a comparative investigation for sulfur and phosphorus inclusion to the sidewalls of MWCNTs was carried out using density functional theory calculations. The results of the computational study showed that both phosphorus and sulfur atoms prefer to bind among themselves rather than adsorbing directly on carbon nanotubes (CNT). Furthermore, cluster calculations revealed that phosphorus atoms more likely form carbonaceous clusters which result in a decrease in the number of free carbon atoms that can be used for CNT formation. Therefore, we concluded that

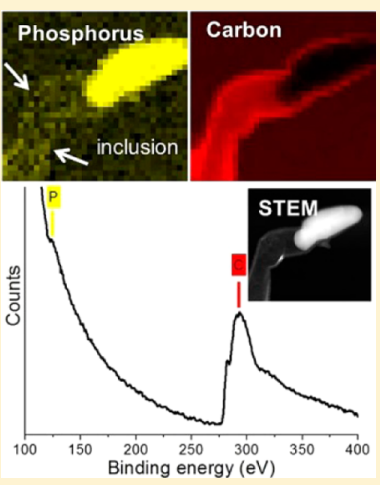
MWCNT growth might be hindered (promoted) in a phosphorus (sulfur) rich environment which results in needle like phosphorus containing MWCNTs.

\section{INTRODUCTION}

Boron, nitrogen, and phosphorus are commonly used as dopants for tailoring the electronic properties of carbon nanotubes (CNT). ${ }^{1-3}$ All boron doped CNTs display p-type properties, whereas nitrogen and phosphorus doped CNTs have n-type electronic structures caused by incorporated electron donor sites. ${ }^{4}$ Doping plays a key role for the building of electronic devices using CNTs. Hence, there are reports of CNTs with modified electronic properties to find future applications as field emitters, fuel cell electrodes, and protein immobilizators. $^{5-7}$

Beside their effect on the electronic properties, changes in the morphology of CNTs are also reported due to the inclusion of dopants. ${ }^{8-10}$ For instance, it is reported that "bamboo" and "matchstick" morphologies encountered for CNTs are a direct result of doping by nitrogen and phosphorus, respectively. ${ }^{9,11}$ Moreover, substitutional inclusion of phosphorus atoms enhances the chemical affinity of CNTs toward acceptor molecules due to the favorable change in localized charge densities. ${ }^{12}$ This may allow the use of phosphorus doped CNTs as ultrasensitive molecular sensors and catalyst supports. ${ }^{13,14}$ However, in situ doping during the synthesis ${ }^{13,15,16}$ has added challenges of overcoming the adverse effect of phosphorus on the catalytic activity of metallic catalysts and increased disorder in the carbon network.
In the present study, we report a new route for the synthesis of phosphorus containing multiwalled carbon nanotubes (MWCNT) by the pyrolysis of dehydrated sucrose. Phosphoric acid $\left(\mathrm{H}_{3} \mathrm{PO}_{4}\right)$ was used both as the dehydrating agent and the phosphorus source throughout the experiments. In our previous study, we investigated the effect of sulfur on the growth and the morphology of CNTs. ${ }^{17}$ It was found that the sulfur only affected the catalytic activity of catalyst particles used for the synthesis of CNTs. Although sulfur and phosphorus elements are neighbors in the periodic table, we did not find any evidence for the inclusion of sulfur to the carbon network of CNTs. In this study, we provide experimental evidence for the presence of phosphorus in the CNTs synthesized by the pyrolysis method, and also present a theoretical underpinning for this through density functional theory (DFT) calculations. Furthermore, our computational study explains the markedly different behavior observed between sulfur and phosphorus.

Received: June 13, 2013

Revised: October 13, 2013

Published: October 14, 2013 

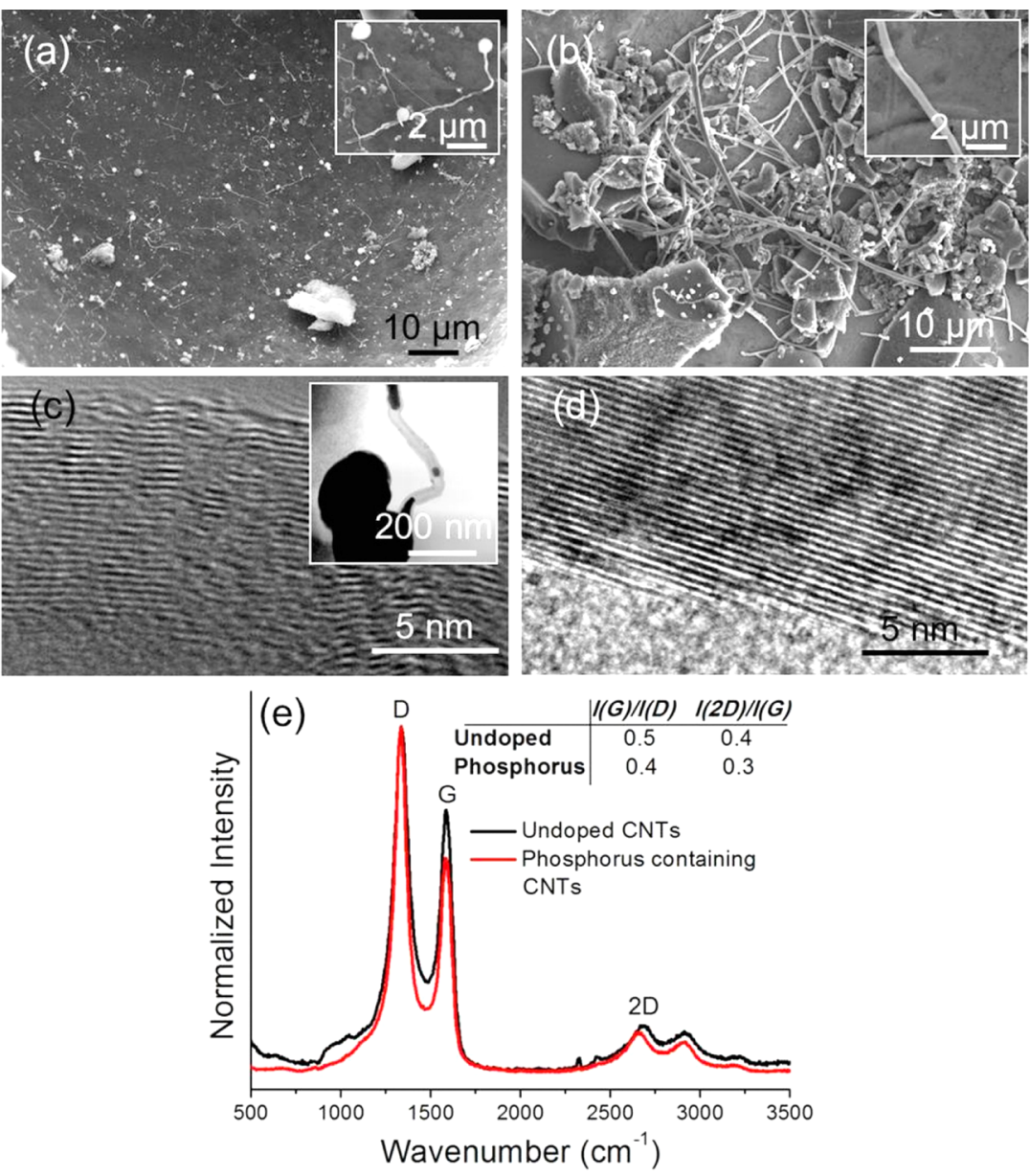

Figure 1. SEM images of MWCNTs synthesized using (a) $\mathrm{H}_{3} \mathrm{PO}_{4}$ (magnified image as inset) and (b) $\mathrm{H}_{2} \mathrm{SO}_{4}$ (magnified image as inset). HRTEM images of the MWCNTs synthesized using (c) $\mathrm{H}_{3} \mathrm{PO}_{4}$ (STEM image as inset) and (d) $\mathrm{H}_{2} \mathrm{SO}_{4}$. (e) Raman analysis of MWCNT containing pyrolysis product synthesized using $\mathrm{H}_{2} \mathrm{SO}_{4}$ and $\mathrm{H}_{3} \mathrm{PO}_{4}$ (black and red lines represent the undoped and phosphorus containing MWCNTs, respectively.). The intensity ratios of $\mathrm{D}, \mathrm{G}$, and $2 \mathrm{D}$ bands are provided in Raman spectra.

\section{MATERIAL AND METHODS}

2.1. Experimental Procedure. MWCNTs were synthesized using the pyrolysis technique as described in our previous study. ${ }^{17}$ In the first step of MWCNT synthesis, $5 \mathrm{~g}$ of carbon source (sucrose) and $25 \mathrm{mg}$ of catalyst $(\mathrm{Fe}, \mathrm{Ni}$, and $\mathrm{Cr}$ powder mixture) precursors were mixed and ground to a fine powder using a mortar. A 1:1 mixture of powdered $\mathrm{Fe}(\geq 99.9 \%)$ and $\mathrm{Ni}$ $(\geq 99.9 \%)$ was used for the catalyst. Subsequently, $5 \mathrm{~mL}$ of concentrated $\mathrm{H}_{3} \mathrm{PO}_{4}(85 \%)$ solution was added to the mixture. $\mathrm{H}_{3} \mathrm{PO}_{4}$ is a strong dehydrating acid, therefore sucrose mixture gets dehydrated and thus carbonized upon the introduction of the acid. In the final step, the carbonized mixture was pyrolyzed in an atmosphere controlled furnace under flowing $\operatorname{Ar}$ (99.99\%) atmosphere at $1330^{\circ} \mathrm{C}$ for $4 \mathrm{~h}$. The resultant pyrolysis product was analyzed using scanning electron microscope (SEM), transmission electron microscope (TEM), energy dispersive Xray spectroscopy (EDX), electron energy loss spectroscopy (EELS), and Raman spectroscopy.

2.2. Theoretical Calculations. We have performed $\mathrm{DFT}^{18,19}$ based pseudo-potential plane wave calculations using Vienna ab initio simulation package program $(\text { VASP })^{20,21}$ and have investigated the geometrical changes in the system by the introduction of phosphorus or sulfur atoms. The ions were described by projector-augmented-wave potentials. $^{22,23}$ Generalized gradient approximation (Perdew-
Wang 91 type $)^{24}$ was employed for exchange-correlation potential. Energy cutoff for plane waves was set to $500 \mathrm{eV}$. K-points were defined by Monkhorst-Pack mesh ${ }^{25}$ to carry out the Brilluoin zone integrations with the smearing parameter set as $0.08 \mathrm{eV}$. The energy convergence was within $10^{-5} \mathrm{eV}$. The systems were relaxed to their minimum energy optimal geometry. From the theoretical point of view, modulating the structure and electronic properties of CNTs is a well-studied subject. For example, doping ${ }^{12,14,26-31}$ and chemical functionalization $^{30,31}$ are tried for this purpose. Among these, doping of CNTs with phosphorus atom is promising for further applications and also investigated through several computational studies. ${ }^{4,12,14,26}$ Note that graphene, a two-dimensional structure, can be used to describe CNTs having large diameters with small curvature. ${ }^{12,26,32}$ After all, we used graphene models to describe the CNTs in the computational part of the study.

\section{RESULTS AND DISCUSSION}

SEM image of the pyrolysis product carbonized by $\mathrm{H}_{3} \mathrm{PO}_{4}$ shows that the yielding material contains both amorphous carbon and randomly scattered tiny MWCNTs (Figure 1a). Although the diameter of these MWCNTs reached $60 \mathrm{~nm}$, their lengths extended to several micrometers. In our previous study, it was shown that MWCNTs were successfully synthesized using sulfuric acid $\left(\mathrm{H}_{2} \mathrm{SO}_{4}\right)$ instead of $\mathrm{H}_{3} \mathrm{PO}_{4}$ as a carbon- 

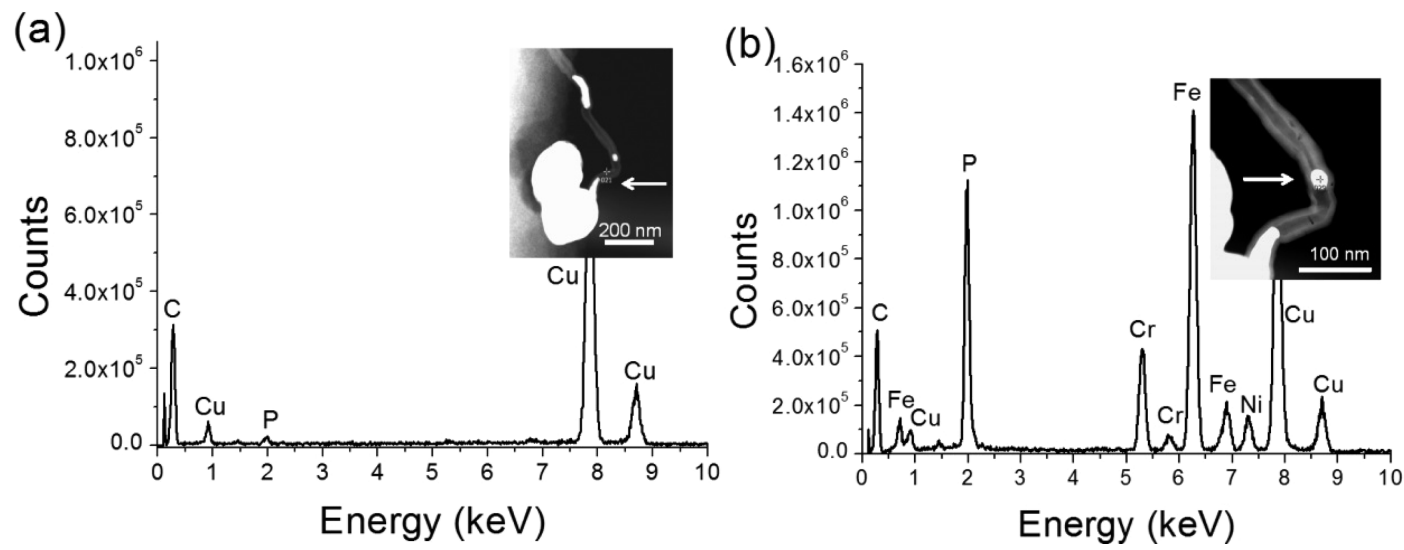

Figure 2. EDX analysis performed using TEM both from (a) the sidewalls and (b) the catalyst particle; iron, nickel, and chromium mixture, indicated the presence of phosphorus both inside the sidewalls and the catalyst particle. The Cu signal originated from TEM grid.
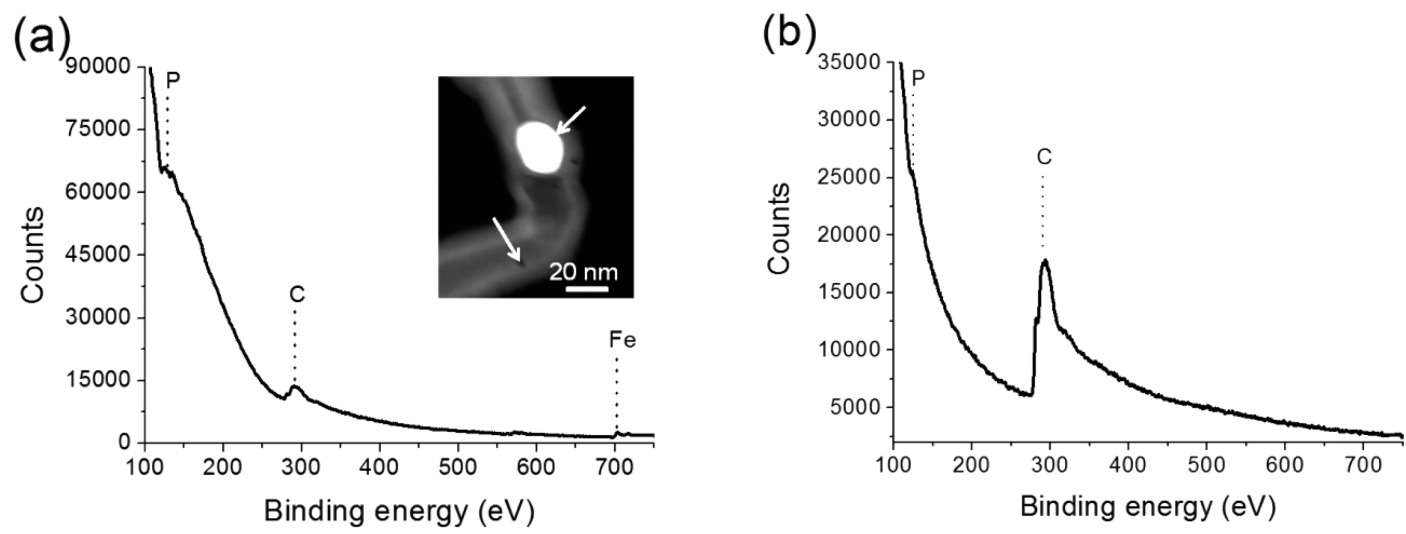

Figure 3. (a) EELS analysis on the catalyst particle trapped inside the CNT showing a high amount of phosphorus edge and (b) EELS data from the sidewalls of CNT showing a lower amount of phosphorus edge. Arrows at the inset image point where spectra in panels a and b were taken.

ization agent in the same manner, and it was found that sulfur was only present inside the catalyst particle but not in the carbon network ${ }^{17}$ (Figure $1 \mathrm{~b}$ ). In the rest of this paper, CNTs synthesized using $\mathrm{H}_{2} \mathrm{SO}_{4}$ are called as undoped MWCNTs.

When the SEM images of the pyrolysis products synthesized by $\mathrm{H}_{2} \mathrm{SO}_{4}$ and $\mathrm{H}_{3} \mathrm{PO}_{4}$ are compared, a significant difference in the size and length of MWCNTs was observed (Figure 1a,b). MWCNTs synthesized using $\mathrm{H}_{3} \mathrm{PO}_{4}$ were much shorter and smaller in diameter than the undoped MWCNTs (inset images in Figure 1a,b). Furthermore, examination of high resolution TEM (HRTEM) images shows that the graphitization of sidewalls of the MWCNTs grown in phosphorus rich environment was poor in quality compared to the undoped ones (Figure 1, panels $c$ and $d$, respectively). The effect of phosphorus on the structure of CNTs was also apparent in the Raman spectrum as presented in Figure 1e. The resultant pyrolysis product from $\mathrm{H}_{3} \mathrm{PO}_{4}$ possessed relatively more structural defects as indicated by the lower $I(\mathrm{G} / \mathrm{D})$ ratio (Figure 1c). In addition, the lower $I(2 \mathrm{D} / \mathrm{G})$ ratio pointed out that MWCNTs had a poorly crystallized structure compared to the undoped MWCNTs which was consistent with the HRTEM images.

According to SEM images, the observed differences between undoped and phosphorus containing MWCNTs were not limited to their size and structure, but their morphology was also strikingly differing. MWCNTs synthesized using $\mathrm{H}_{3} \mathrm{PO}_{4}$ generally emerged from a small catalyst particle which is significantly larger than the diameter of MWCNT, and the diameter was found to narrow through the "tail" resembling a needle shape with the catalyst particle acting as the "head of the needle" (inset of Figure 1a). Similar growth behavior was also observed by other research groups, and it was attributed to the phosphorus inclusion. ${ }^{11,33,34}$ By developing this idea further, we also address the shorter and smaller needle like CNT growth with phosphorus inclusion. Phosphorus content could deactivate the large portion of catalyst particle which can result in carbon coating on the catalyst surface and left only a small active part for the CNT growth. In order to develop a better understanding for the role of phosphorus in the growth, EDX analysis using TEM was performed on the MWCNT synthesized using $\mathrm{H}_{3} \mathrm{PO}_{4}$. A poor signal for phosphorus was detected from the sidewalls of MWCNT (Figure 2a), whereas there was a significant amount of phosphorus signal coming from the catalyst (Figure 2b). Also, EDX spectra from the catalyst shows that it is a mixture of iron and nickel trapped into the hollow part of a MWCNT (inset of Figure 2b). The phosphorus concentration inside the active metal catalyst trapped into the CNT was found to be around 13\% (at.) by quantifying the EDX spectrum. Note that the eutectic point for this percentage of phosphorus is at $1048{ }^{\circ} \mathrm{C} .^{35}$ Therefore, in our growth temperature $\left(1300{ }^{\circ} \mathrm{C}\right)$, the catalyst formed eutectic with phosphorus $(\mathrm{Fe} / \mathrm{P})$ at liquid state. The hollow parts of CNTs were partially filled by the catalyst due to its liquid state during the growth.

Phosphorus is known to lower the catalytic activity of metal catalysts used in the oxidative alkanes conversion. ${ }^{36}$ In addition, 


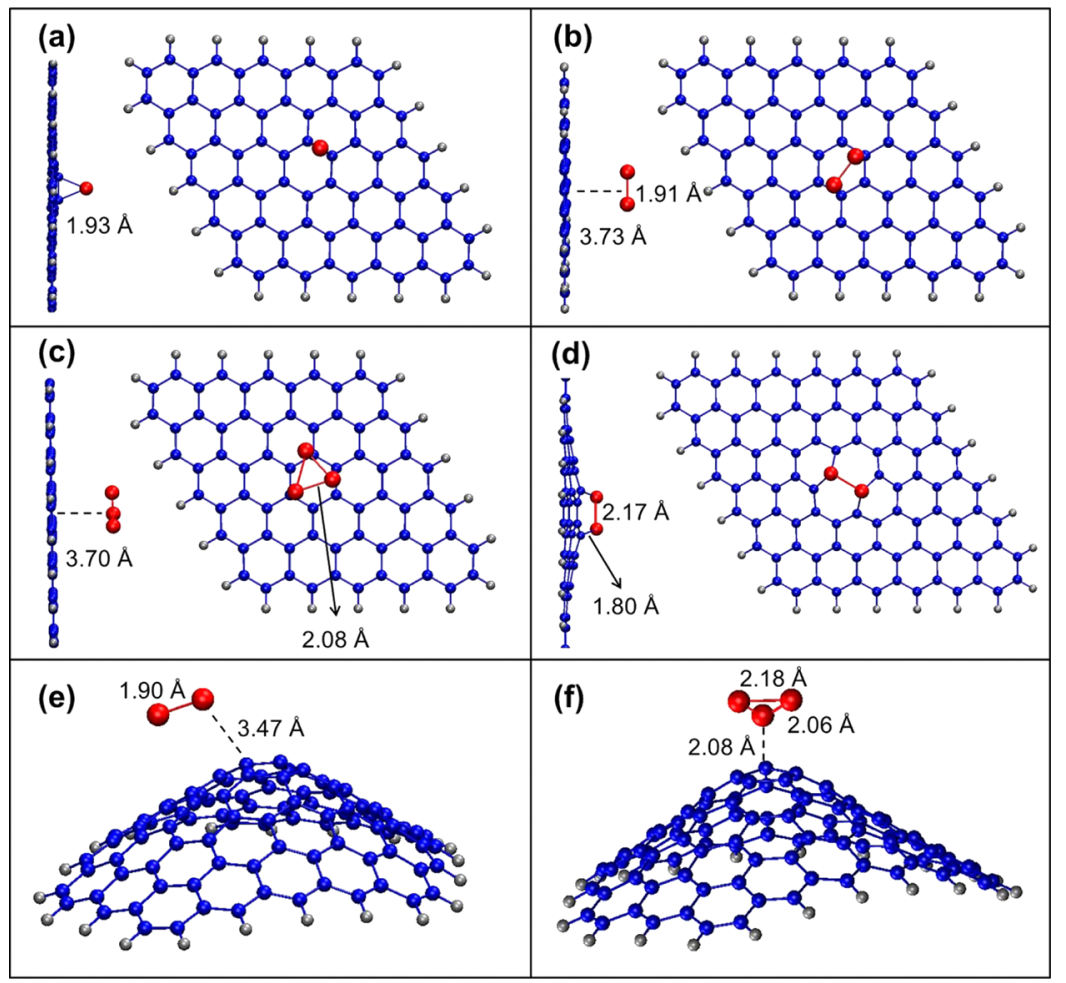

Figure 4. Optimized structures of various phosphorus atoms interacting with the carbon network. Adsorption of (a) single phosphorus atom in the bridge position, (b) two and (c) three phosphorus atoms over the graphene layer, (d) two phosphorus atoms on the double vacancy of the graphene layer, and (e) two and (f) three phosphorus atoms over the kink structure. (Small blue and large red dots represent carbon and phosphorus atoms, respectively.)

Terrones et al. reported that the iron phosphide particles $\left(\mathrm{Fe}_{2} \mathrm{P}\right.$ and $\mathrm{Fe}_{3} \mathrm{P}$ ) were not active compared to the metallic particles in CNT growth. ${ }^{8}$ On the contrary, phosphorus was also reported as a cocatalyst for the sequential growth of CNTs. ${ }^{11}$ In this study, we found that phosphorus did not fully hinder the growth yet it yielded tiny MWCNTs compared to the sulfur case. ${ }^{17}$ Since the catalyst is in a liquid state during the synthesis, the catalyst surface would be refreshed, and new active growth sites would appear. Hence, this might keep the growth continuous even if the phosphorus is present in the media.

Although EDX analysis showed a significant signal for phosphorus, it is not enough to claim the presence of phosphorus inside the sidewalls. In order to provide further evidence, EELS analysis was performed on the MWCNTs synthesized using $\mathrm{H}_{3} \mathrm{PO}_{4}$ (Figure 3). According to the spectrum in Figure 3a, there is an apparent phosphorus edge for the catalyst which was trapped inside the hollow part of the MWCNT along with the Fe edge at $720 \mathrm{eV}$. This indicated that there is phosphorus content inside the $\mathrm{Fe}$ catalyst which supports the outcome of the EDX spectrum (Figure 2b). Furthermore, EELS data shown in Figure 3 pointed out that phosphorus was not only found at the catalyst particle but also present inside the sidewalls of CNTs.

In order to provide a further understanding of the phosphorus-carbon network interaction at the atomistic scale, we have performed DFT calculations. We needed to place phosphorus atoms in various positions over sidewalls of MWCNTs to describe their interaction. Since the diameter of MWCNTs we synthesized was around $30 \mathrm{~nm}$, it was very difficult to model such large structures from first principle calculations. Fortunately, a larger diameter means smaller curvature so we could represent them by planar graphene layers. A $6 \times 6$ graphene unit cell was used to simulate the outmost layer of CNT and then phosphorus atoms were brought in contact with it. Moreover, there were defected and bent regions as well as the junctions on the synthesized CNTs. Therefore, defected graphene and kink structures were also included in the investigation of the phosphorus interaction with CNTs. We placed different number of phosphorus atoms at different possible positions over these graphene layers. For several initial geometries, we performed structure optimization by minimizing total energy. Then, we calculated the binding energy $\left(E_{\text {binding }}\right)$ of these final structures as follows:

$$
E_{\text {binding }}=E_{\text {total }}-E_{\text {grap }}-n_{\mathrm{P}} \mu_{\mathrm{P}}
$$

where $E_{\text {total }}$ is the total energy of the system, $E_{\text {grap }}$ is the energy of the graphene layer, $n_{\mathrm{p}}$ is the number, and $\mu_{\mathrm{p}}$ is the chemical potential of phosphorus atoms. In addition, we have also calculated the formation energy $\left(\mathrm{E}_{\text {formation }}\right)$ of the structures by changing the reference from the separated phosphorus atoms to corresponding phosphorus molecules such as dimer, trimer, etc., i.e., replacing $n_{\mathrm{P}} \mu_{\mathrm{P}}$ by $E_{\text {molecule }}$.

Figure 4 summarizes the selected optimized structures with the highest binding energies which are provided in detail in Table 1. A single phosphorus atom was found to be adsorbed over two carbons in the bridge position as seen in Figure 4a. When a second phosphorus atom was introduced, they tended to attract each other to form a phosphorus dimer (Figure 4b). Hence, the interaction between the phosphorus and carbon network was weakened and the carbon-phosphorus distance was increased. In a similar manner, a trimer structure was formed in the presence of the third phosphorus atom and moved away from the carbon surface (Figure 4c). This indicates that the phosphorus-phosphorus interaction is stronger than 
Table 1. Binding Energies for Optimized Configurations

\begin{tabular}{|c|c|c|c|c|}
\hline \multirow[b]{2}{*}{ system } & \multicolumn{2}{|c|}{ phosphorus } & \multicolumn{2}{|c|}{ sulfur } \\
\hline & $\begin{array}{c}E_{\text {binding }} \\
(\mathrm{eV})\end{array}$ & $\begin{array}{c}E_{\text {formation }} \\
(\mathrm{eV})\end{array}$ & $\begin{array}{c}E_{\text {binding }} \\
(\mathrm{eV})\end{array}$ & $\begin{array}{l}E_{\text {formation }} \\
(\mathrm{eV})\end{array}$ \\
\hline \multicolumn{5}{|c|}{ Graphene } \\
\hline single atom & -1.66 & -1.66 & -1.69 & -1.69 \\
\hline dimer (physisorption) & -9.02 & -0.06 & -6.49 & -0.22 \\
\hline dimer (chemisorption) & -6.58 & 2.37 & & \\
\hline separated atoms & -3.77 & 5.18 & -3.43 & 2.84 \\
\hline trimer & -13.52 & -0.12 & -10.53 & 0.30 \\
\hline chain & -12.61 & 0.80 & -10.41 & 0.42 \\
\hline \multicolumn{5}{|c|}{ Graphene with Vacancy } \\
\hline single vacancy + single atom & -9.86 & -9.86 & -8.08 & -8.08 \\
\hline double vacancy + single atom & -7.50 & -7.50 & -5.25 & -5.25 \\
\hline $\begin{array}{l}\text { double vacancy }+2 \text { atoms } \\
\text { (opposite sides) }\end{array}$ & -12.42 & -3.46 & -9.71 & -3.44 \\
\hline $\begin{array}{l}\text { double vacancy }+2 \text { atoms } \\
\text { (same sides) }\end{array}$ & -12.57 & -3.61 & -7.62 & -1.35 \\
\hline \multicolumn{5}{|c|}{ Kink Structure } \\
\hline $\begin{array}{l}\text { on top of a } \mathrm{C}-\mathrm{C} \text { bond in } \\
\text { pentagon }\end{array}$ & -2.68 & -2.68 & -2.78 & -2.78 \\
\hline $\begin{array}{l}\text { on top of a } \mathrm{C}-\mathrm{C} \text { bond away } \\
\text { from pentagon }\end{array}$ & -2.72 & -2.72 & -2.75 & -2.75 \\
\hline dimer (physisorption) & -9.05 & -0.09 & & \\
\hline $\begin{array}{l}\text { dimer (single atom } \\
\text { chemisorption) }\end{array}$ & -6.80 & 2.15 & -6.89 & -0.62 \\
\hline dimer (chemisorption) & -8.44 & 0.51 & -6.40 & -0.12 \\
\hline trimer (physisorption) & -13.63 & -0.23 & -10.53 & 0.30 \\
\hline trimer (chemisorption) & -14.44 & -1.05 & & \\
\hline chain & -12.59 & 0.81 & -11.08 & -0.24 \\
\hline $\begin{array}{l}\text { dimer }(\text { physisorption })+\text { single } \\
\text { atom }\end{array}$ & -11.90 & 1.50 & & \\
\hline $\begin{array}{l}\text { dimer }(\text { chemisorption })+\text { single } \\
\text { atom }\end{array}$ & -11.67 & 1.73 & -9.54 & 1.30 \\
\hline
\end{tabular}

the carbon-phosphorus interaction; thus, phosphorus atoms could not be incorporated into the sidewalls of CNTs. However, when there is a defected carbon network, such as double carbon vacancy shown in Figure 4d, phosphorus atoms (dimer) saturated the dangling bonds of carbon atoms around the vacancies. Apart from these, introduction of pentagon rings led to the bending of graphene structures as shown in Figure $4 \mathrm{e}, \mathrm{f}$. Bent regions or junctions of CNTs can be modeled by these kink structures. Interaction of phosphorus atoms with these structures was similar to those of the planar cases discussed previously. In conclusion, in the absence of defects on the graphene layer, phosphorus atoms have a tendency to aggregate and get away from the carbon network.

In order to further quantify the phosphorus interaction with CNTs, we compared these results to the sulfur containing cases since we observed differences in CNT morphologies even though a similar synthesis technique was conducted using sulfur containing precursor as reported in our previous study. ${ }^{17}$ In that study, similar DFT results have been obtained for the sulfur-carbon network. ${ }^{17}$ This indicates that phosphorus and sulfur atoms do not join to the surface of a complete CNT, and there is not a significant difference in their behaviors toward a vacancy as well. Therefore, in order to explain the effect of phosphorus (sulfur) on CNTs, we need to investigate the details of the growth by checking different sized phosphoruscarbon and sulfur-carbon containing clusters.

Our cluster calculations were not related directly to CNT but about the environment during the growth. We calculated the stabilities of $\mathrm{C}_{x} \mathrm{P}_{y}$ and $\mathrm{C}_{x} \mathrm{~S}_{y}$ clusters having five atoms at most.
We formed several initial structures with initial bond lengths around $2 \AA$. Then, we discussed energetics of the optimized structures (Table 2) which are presented in Figure 5. The

Table 2. Total Energies for the Systems Shown in Figure 5

\begin{tabular}{|c|c|c|c|}
\hline \multirow[b]{2}{*}{ Figure 5} & \multirow[b]{2}{*}{ system } & \multicolumn{2}{|c|}{$E_{\text {total }}(\mathrm{eV})$} \\
\hline & & $X=\mathrm{P}$ & $X=\mathrm{S}$ \\
\hline a & $\mathrm{C}_{1} \mathrm{X}_{1}$ & -8.60 & -10.20 \\
\hline $\mathrm{b}$ & $\mathrm{C}_{1} \mathrm{X}_{2}$ & -15.49 & -16.56 \\
\hline c & $\mathrm{C}_{2} \mathrm{X}_{1}$ & -16.86 & -16.12 \\
\hline d & $\mathrm{C}_{1} \mathrm{X}_{3}$ & -20.75 & -18.14 \\
\hline e & $\mathrm{C}_{2} \mathrm{X}_{2}$ & -23.34 & -20.52 \\
\hline $\mathrm{f}$ & $\mathrm{C}_{3} \mathrm{X}_{1}$ & -25.33 & -23.67 \\
\hline$g$ & $\mathrm{C}_{1} \mathrm{X}_{4}$ & -27.01 & -23.34 \\
\hline $\mathrm{h}$ & $\mathrm{C}_{2} \mathrm{X}_{3}$ & -28.92 & -27.02 \\
\hline $\mathrm{i}$ & $\mathrm{C}_{3} \mathrm{X}_{2}$ & -32.27 & -32.85 \\
\hline $\mathrm{j}$ & $\mathrm{C}_{4} \mathrm{X}_{1}$ & -33.65 & -31.30 \\
\hline $\mathrm{k}$ & $\mathrm{C}_{1} \mathrm{X}_{4}$ & & -21.37 \\
\hline 1 & $\mathrm{C}_{2} \mathrm{X}_{3}$ & & -26.75 \\
\hline $\mathrm{m}$ & $\mathrm{C}_{4} \mathrm{X}_{1}$ & & -29.22 \\
\hline $\mathrm{n}$ & $\mathrm{C}_{4} \mathrm{X}_{1}$ & & -28.95 \\
\hline dimers & $E_{\text {total }}(\mathrm{eV})$ & & \\
\hline $\mathrm{C}_{2}$ & -9.00 & & \\
\hline $\mathrm{P}_{2}$ & -9.02 & & \\
\hline $\mathrm{S}_{2}$ & -6.48 & & \\
\hline
\end{tabular}

carbon-phosphorus and carbon-sulfur bond lengths $(\sim 1.55$ A) measured from their dimer structures, shown in Figure 5a, were used as references for the growth of their clusters. Carbon monosulfide are known as the metastable intermediated phase. ${ }^{37}$ When second phosphorus or sulfur atoms were introduced (Figure 5b), the bond lengths were increased slightly to form a chain with carbon atom in the center instead of a triangular structure. Carbon-carbon bond lengths in Figure $5 \mathrm{c}$ show that the phosphorus atom pulls the electron of the carbon atom in the middle more than the sulfur atom, so the carbon-phosphorus interaction is a strong one. As we increased the total number of atoms, various planar geometries appeared as their minimum energy configurations (Figure 5dj). In our $C_{x} S_{y}$ calculations, we have observed additional configurations with close energies to the optimum ones (Figure $5 \mathrm{~g}, \mathrm{~h}, \mathrm{j})$ as presented in Figure $5 \mathrm{k}-\mathrm{n}$. In these, larger clusters split into smaller ones including carbon monosulfide frequently. Such behavior was not observed for $\mathrm{C}_{x} \mathrm{P}_{y}$ cases in which atoms ended up intact clusters. These findings would provide an explanation to our following experimental results. First, phosphorus atoms make cluster with carbon atoms decreasing the number of free carbon that can be used for CNTs to be constructed. Therefore, CNTs cannot grow much and they become tinier and low in number. The situation is just opposite for $C_{x} S_{y}$ systems because they tend to break up; hence, the number of free carbon atoms increases which might be the cause of the promotion of the CNT growth. ${ }^{17}$ Second, when a phosphorus atom enters into the structure of a wall during the growth, it may tend to form a cluster, and this would result in a local bump inside the CNT walls. Furthermore, this might be preventing the structure to form a well graphitized surface. Third, since clusters with sulfur atoms have a tendency to split, sulfur clusters are rarely observed inside the CNT walls compared to the phosphorus case. In conclusion, CNTs synthesized in the phosphorus rich environment are expected 


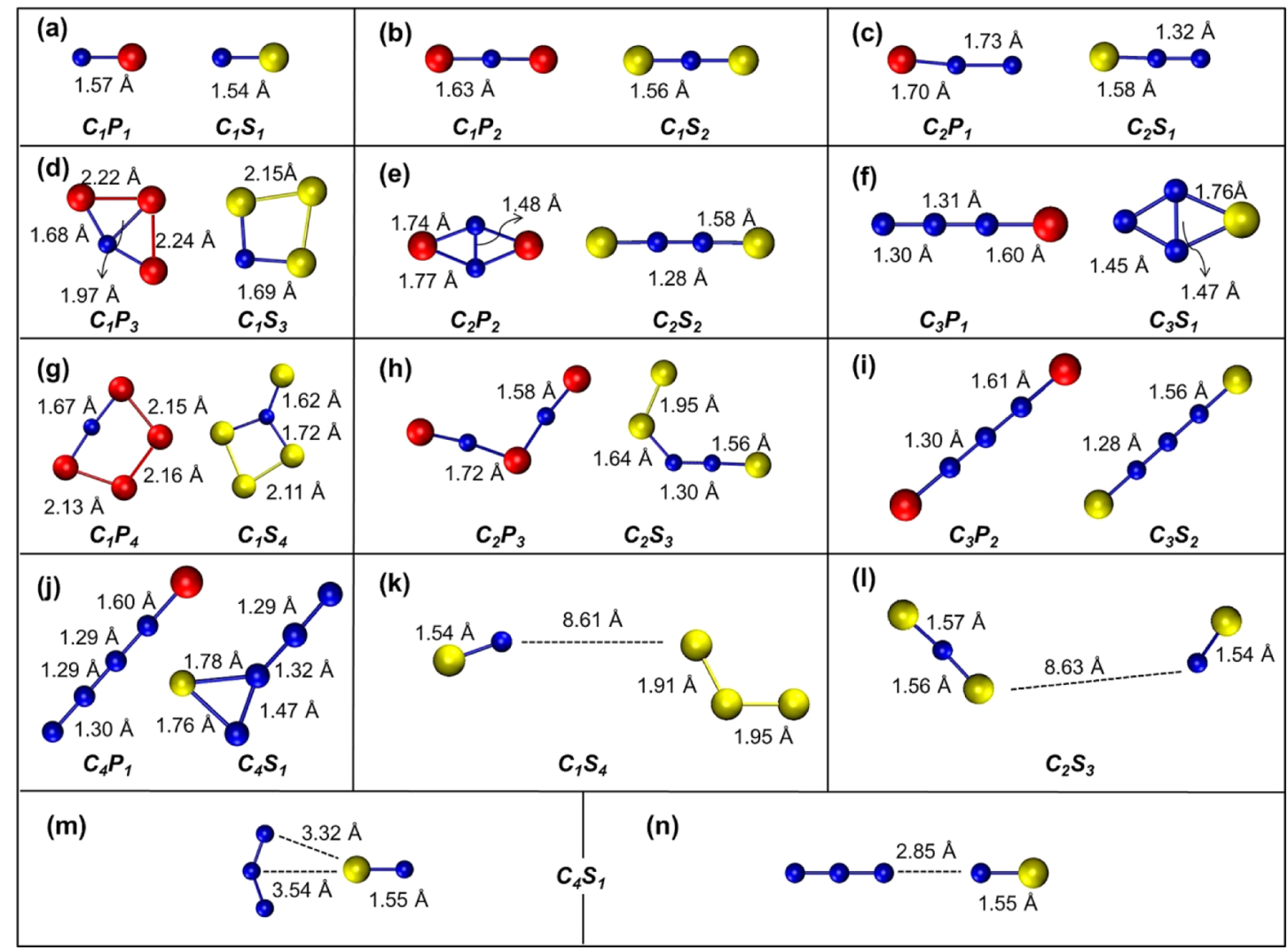

Figure 5. Various $\mathrm{C}_{x} \mathrm{P}_{y}$ and $\mathrm{C}_{x} \mathrm{~S}_{y}$ clusters with $(\mathrm{a}-\mathrm{j})$ optimized minimum energy geometry and $(\mathrm{k}-\mathrm{n})$ additionally observed $\mathrm{C}_{x} \mathrm{~S}_{y}$ structures with close energy to the optimum ones. (Small blue, large red, and large yellow dots represent carbon, phosphorus, and sulfur atoms, respectively.)

to be smaller in size, lower in quantity, and poorly graphitized in contrast to the ones synthesized in the sulfur rich environment. Furthermore, our findings support that phosphorus atoms more likely form a carbonaceous cluster over the catalyst particle.

\section{CONCLUSIONS}

Needle like phosphorus containing MWCNTs were synthesized by the pyrolysis method using $\mathrm{H}_{3} \mathrm{PO}_{4}$ as a dehydrating agent. According to the SEM and TEM images, these MWCNTs were small in size, low in quantity, and poorly graphitized with respect to the ones synthesized using sulfur containing precursors. The EDX and EELS analysis provided strong evidence for the phosphorus inclusion to the sidewalls of MWCNTs, besides it was present at the catalyst particle inside the hollow part of the CNT. These experimental findings were further supported by DFT calculations. Accordingly, both phosphorus and sulfur atoms prefer to bind among themselves rather than adsorbing directly on CNTs. Indeed, phosphorus atoms more likely form a carbonaceous cluster over the catalyst particle indicated by DFT calculations of $\mathrm{C}_{x} \mathrm{P}_{y}$ and $\mathrm{C}_{x} \mathrm{~S}_{y}$ cluster systems. Phosphorus atoms make cluster with carbon atoms decreasing the number of free carbon atoms that can be used for CNT formation and hinders the growth. Whereas, sulfur atoms tend to disassociate the $\mathrm{C}_{x} \mathrm{~S}_{y}$ hence the number of free carbon atoms increases that promotes the CNT growth. In conclusion, phosphorus inclusion is realized on sidewalls and/ or inside the MWCNTs; however, these are smaller in size, lower in quantity, and poorly graphitized as compared to the undoped MWCNTs synthesized in the sulfur rich environment.

\section{AUTHOR INFORMATION}

\section{Corresponding Author}

*E-mail: bengu@fen.bilkent.edu.tr; erbengu@gmail.com. Tel: +90-0312-290-2153. Fax: +90-312-266-4068.

\section{Notes}

The authors declare no competing financial interest.

\section{ACKNOWLEDGMENTS}

G.K.-D. and H.S.S. acknowledge TUBITAK-BIDEB for the financial support.

\section{REFERENCES}

(1) Liu, H.; Zhang, Y.; Li, R.; Sun, X.; Désilets, S.; Abou-Rachid, H.; Jaidann, M.; Lussier, L.-S. Structural and Morphological Control of Aligned Nitrogen-Doped Carbon Nanotubes. Carbon 2010, 48, 14981507.

(2) Koós, A. A.; Dillon, F.; Obraztsova, E. A.; Crossley, A.; Grobert, N. Comparison of Structural Changes in Nitrogen and Boron-Doped Multi-Walled Carbon Nanotubes. Carbon 2010, 48, 3033-3041.

(3) Borowiak-Palen, E.; Pichler, T.; Graff, A.; Kalenczuk, R. J.; Knupfer, M.; Fink, J. Synthesis and Electronic Properties of B-Doped Single Wall Carbon Nanotubes. Carbon 2004, 42, 1123-1126.

(4) Maciel, I. O.; Campos-Delgado, J.; Cruz-Silva, E.; Pimenta, M. A.; Sumpter, B. G.; Meunier, V.; Lopez-Urias, F.; Munoz-Sandoval, E.; Terrones, H.; Terrones, M.; et al. Synthesis, Electronic Structure, and Raman Scattering of Phosphorus-Doped Single-Wall Carbon Nanotubes. Nano Lett. 2009, 9, 2267-2272.

(5) Charlier, J. C.; Terrones, M.; Baxendale, M.; Meunier, V.; Zacharia, T.; Rupesinghe, N. L.; Hsu, W. K.; Grobert, N.; Terrones, H.; Amaratunga, G. A. J. Enhanced Electron Field Emission in BDoped Carbon Nanotubes. Nano Lett. 2002, 2, 1191-1195. 
(6) Paul, D. R.; Koros, W. J.; Liu, R. Y. F.; Hu, Y. S.; Baer, E.; Hiltner, A.; Keith, H. D.; Cohen, R. E.; Bellare, A.; Albalak, R. J.; et al. Nitrogen-Doped Carbon Nanotube. Science 2009, 323, 760-764.

(7) Jiang, K.; Schadler, L. S.; Siegel, R. W.; Zhang, X.; Zhang, H.; Terrones, M. Protein Immobilization on Carbon Nanotubes via a Two-Step Process of Diimide-Activated Amidation. J. Mater. Chem. 2004, 14, 37-39.

(8) Cruz-Silva, E.; Cullen, D. A.; Gu, L.; Romo-Herrera, J. M.; Munoz-Sandoval, E.; Lopez-Urias, F.; Sumpter, B. G.; Meunier, V.; Charlier, J.; Smith, K. D. J.; et al. Heterodoped Nanotubes: Theory, Synthesis, and Characterization of Phoshorus - Nitrogen Doped Multiwalled Carbon Nanotubes. ACS Nano 2008, 2, 441-448.

(9) Villalpando-Paez, F.; Zamudio, A.; Elias, A. L.; Son, H.; Barros, E. B.; Chou, S. G.; Kim, Y. A.; Muramatsu, H.; Hayashi, T.; Kong, J.; et al. Synthesis and Characterization of Long Strands of Nitrogen-Doped Single-Walled Carbon Nanotubes. Chem. Phys. Lett. 2006, 424, 345352.

(10) Nxumalo, E. N.; Letsoalo, P. J.; Cele, L. M.; Coville, N. J. The Influence of Nitrogen Sources on Nitrogen Doped Multi-Walled Carbon Nanotubes. J. Organomet. Chem. 2010, 695, 2596-2602.

(11) Jourdain, V.; Paillet, M.; Almairac, R.; Loiseau, A.; Bernier, P. Relevant Synthesis Parameters for the Sequential Catalytic Growth of Carbon Nanotubes. J. Phys. Chem. B 2005, 109, 1380-1386.

(12) Cruz-Silva, E.; Lo, F.; Mun, E.; Sumpter, B. G.; Terrones, H.; Charlier, J.; Meunier, V.; Terrones, M. Electronic Transport and Mechanical Properties of Phosphorous and Phosphorous -Nitrogen Doped Carbon Nanotubes. ACS Nano 2009, 3, 1913-1921.

(13) Koos, A. A.; Nicholls, R. J.; Dillon, F.; Kertesz, K.; Biro, L. P.; Crossley, A.; Grobert, N. Tailoring Gas Sensing Properties of MultiWalled Carbon Nanotubes by In Situ Modification With Si, P, and N. Carbon 2012, 50, 2816-2823.

(14) Cruz-Silva, E.; Lopez-Urias, F.; Munoz-Sandoval, E.; Sumpter, B. G.; Terrones, H.; Charlier, J.-C.; Meunier, V.; Terrones, M. Phosphorus and Phosphorus-Nitrogen Doped Carbon Nanotubes for Ultrasensitive and Selective Molecular Detection. Nanoscale 2011, 3, $1008-1013$.

(15) Yu, D.; Xue, Y.; Dai, L. Vertically Aligned Carbon Nanotube Arrays Co-Doped with Phosphorus and Nitrogen as Efficient MetalFree Electrocatalysts for Oxygen Reduction. J. Phys. Chem. Lett. 2012, 3, 2863-2870.

(16) Cao, Y.; Yu, H.; Tan, J.; Peng, F.; Wang, H.; Li, J.; Zheng, W.; Wong, N. B. Nitrogen-, Phosphorous- and Boron-Doped Carbon Nanotubes as Catalysts for the Aerobic Oxidation of Cyclohexane. Carbon 2013, 57, 433-442.

(17) Kucukayan, G.; Ovali, R.; Ilday, S.; Baykal, B.; Yurdakul, H.; Turan, S.; Gulseren, O.; Bengu, E. An Experimental and Theoretical Examination of the Effect of Sulfur on the Pyrolytically Grown Carbon Nanotubes from Sucrose-Based Solid State Precursors. Carbon 2011, 49, 508-517.

(18) Kohn, W.; Sham, L. J. Self-Consistent Equations Including Exchange and Correlation Effects. Phys. Rev. 1965, 140, A1133A1138.

(19) Hohenberg, P.; Kohn, W. Inhomogeneous Electron Gas. Phys. Rev. 1964, 136, B864-B871.

(20) Kresse, G.; Hafner, J. Ab Initio Molecular Dynamics for OpenShell Transition Metals. Phys. Rev. B 1993, 48, 13115-13118.

(21) Kresse, G.; Hafner, J. Ab Initio Molecular Dynamics for Liquid Metals. Phys. Rev. B 1993, 47, 558-561.

(22) Blochl, P. E. Projector augmented-wave method. Phys. Rev. B 1994, 50, 17953-17979.

(23) Kresse, G.; Joubert, D. From Ultrasoft Pseudopotentials to the Projector Augmented-Wave Method. Phys. Rev. B 1999, 59, 17581775 .

(24) Perdew, J. P.; Chevary, J. A.; Vosko, S. H.; Jackson, K. A.; Pederson, M. R.; Singh, D. J.; Fiolhais, C. Atoms, Molecules, Solids, and Surfaces: Applications of the Generalized Gradient Approximation for Exchange and Correlation. Phys. Rev. B 1992, 46, 6671-6687.

(25) Monkhorst, H. J.; Pack, J. D. Special Points for Brillouin-Zone Integrations. Phys. Rev. B 1976, 13, 5188-5192.
(26) Wang, H.; Wang, H.; Chen, Y.; Liu, Y.; Zhao, J.; Cai, Q.; Wang, $\mathrm{X}$. Phosphorus-Doped Graphene and $(8,0)$ Carbon Nanotube: Structural, Electronic, Magnetic Properties, and Chemical Reactivity. Appl. Surf. Sci. 2013, 273, 302-309.

(27) Yagi, Y.; Briere, T. M.; Sluiter, M. H. F.; Kumar, V.; Farajian, A. A.; Kawazoe, Y. Stable Geometries and Magnetic Properties of SingleWalled Carbon Nanotubes Doped with 3d Transition Metals: A FirstPrinciples Study. Phys. Rev. B 2004, 69, 075414.

(28) Denis, P. A; Faccio, R; Mombru, A. W. Is It Possible to Dope Single-Walled Carbon Nanotubes and Graphene with Sulfur? Chem. Phys. Phys. Chem. 2009, 10, 715-22.

(29) Lu, X.; Sun, C.; Li, F.; Cheng, H.-M. Selected Absorption Behavior of Sulfur on Single-Walled Carbon Nanotubes by DFT. Chem. Phys. Lett. 2008, 454, 305-309.

(30) Durgun, E.; Dag, S.; Bagci, V.; Gülseren, O.; Yildirim, T.; Ciraci, S. Systematic Study of Adsorption of Single Atoms on a Carbon Nanotube. Phys. Rev. B 2003, 67, 201401.

(31) Feng, H.; Ma, J.; Hu, Z. Nitrogen-Doped Carbon Nanotubes Functionalized by Transition Metal Atoms: A Density Functional Study. J. Mater. Chem. 2010, 20, 1702.

(32) Rana, K.; Kucukayan-Dogu, G.; Sen, H. S.; Boothroyd, C.; Gulseren, O.; Bengu, E. Analysis of Charge Transfer for In Situ Li Intercalated Carbon Nanotubes. J. Phys. Chem. C 2012, 116, 1136411369.

(33) Larrude, D. G.; Maia da Costa, M. E. H.; Monteiro, F. H.; Pinto, A. L.; Freire, F. L. Characterization of Phosphorus-Doped Multiwalled Carbon Nanotubes. J. Appl. Phys. 2012, 111, 064315.

(34) Jourdain, V.; Simpson, E. T.; Paillet, M.; Kasama, T.; DuninBorkowski, R. E.; Poncharal, P.; Zahab, A.; Loiseau, A.; Robertson, J.; Bernier, P. Periodic Inclusion of Room-Temperature-Ferromagnetic Metal Phosphide Nanoparticles in Carbon Nanotubes. J. Phys. Chem. B 2006, 110, 9759-9763.

(35) Massalski, T. B. Binary Alloy Phase Diagrams, 2nd ed.; ASM Intl.: Materials Park, OH, 1990; pp 1746-1749.

(36) Brik, Y.; Kacimi, M.; Ziyad, M.; Bozon-Verduraz, F. TitaniaSupported Cobalt and Cobalt-Phosphorus Catalysts: Characterization and Performances in Ethane Oxidative Dehydrogenation. J. Catal. 2001, 202, 118-128.

(37) Moltzen, E. K.; Klabunde, K. J.; Senning, A. Carbon Monosulfide: A Review. Chem. Rev. 1988, 88, 391-406. 